\title{
Geologia nas Escolas de Ensino Básico: a experiência do Departamento de Geologia da Universidade Federal do Rio de Janeiro
}

\author{
Cícera Neysi de Almeida ${ }^{1}$, Creuza de Araújo², Edson Farias Mello ${ }^{1}$ \\ 'Departamento de Geologia, Instituto de Geociências - IGE0, Universidade Federal do Rio de Janeiro - UFRJ, Rio de Janeiro (RJ), \\ Brasil.e-mail: neysi@geologia.ufrj.br, edson@geologia.ufrj.br \\ ${ }^{2}$ CIEP Brizolão 386, Rio de Janeiro (RJ), Brasil.
}

\section{Manuscrito:}

Recebido: 11/09/2012

Corrigido: 23/10/2013

Aceito: 29/06/2015

Citation: Almeida C.N., Araújo C., Mello E.F. 2015. Geologia nas Escolas de Ensino Básico: a experiência do Departamento de Geologia da Universidade Federal do Rio de Janeiro. Terræ Didatica, 11(3):150161. <http://www.ige.unicamp.br/ terraedidatica/ $>$.

Keywords: Geoscience teaching; scientific divulgation; paradidactic resources.

\begin{abstract}
Geology is not a regular discipline in primary and secondary education in Brazil, and its concepts are not popular, but it is part of everyday life and is valuable in helping people understand the environment in which they live. The Geosciences can improve the knowledge of environmental issues inside and outside the school setting. The University, by vocation, should multiply its production and transfer its knowledge, thus minimizing the gap between academia and society. The Geology Department of IGEO/UFRJ offers courses for teachers, seeking to spread geological knowledge. The interdisciplinary geology practices seek to improve the teaching of Geosciences in the public schools of Rio de Janeiro. Textbook resources have brought the knowledge produced in the Department closer to teachers and students. Around 80 teachers from various state districts were trained, and more than 300 collections of minerals and rocks were distributed, with explanatory guides. The institution thus becomes an agent for improved qualification of basic teaching, providing students and teachers of public schools assistance in developing multipliers of geologic knowledge.
\end{abstract}

\section{INTRODUÇÃO}

A atual comunidade científica que discute temas sobre ensino e aprendizagem é praticamente unânime no que diz respeito à necessidade de integração dos saberes para uma aprendizagem mais significativa. Em relação às leis que tentam dar um direcionamento aos conteúdos desenvolvidos nas escolas, particularmente nos Parâmetros Curriculares Nacionais (PCNs), a interdisciplinaridade tem sido proposta como forma de minimizar a fragmentação entre os diversos saberes e tentar maior aproximação e compreensão à complexa realidade do mundo atual.

Inúmeros cientistas e educadores entre eles Freinet e Piaget apontam para a importância de elementos experimentais no desenvolvimento da aprendizagem, isto é, quanto mais perto da reali- dade e do objeto de estudo melhor será a compreensão do aluno. Isto não significa reduzir o ensino à aparência das coisas, o que seria muito simplista, nem tão pouco achar que o que está mais próximo fisicamente é o mais próximo cognitivamente. Os meios de comunicação, presentes na maioria dos lares, conseguem aproximar realidades distantes e provavelmente a maioria dos brasileiros conheçam mais a paisagem do Vale dos Monumentos, no Arizona (EUA), do que das Serras do Sul do Ceará. Devido aos avanços tecnológicos e primazia de determinadas culturas, um local ou objeto que está fisicamente distante do sujeito pode está mais próximo à sua realidade e experiências do que um mais próximo fisicamente.

Em relação à aprendizagem a única forma de se descobrir o que o indivíduo aprendeu ainda 
é através da exteriorização, isto é por meio das palavras, da escrita, da representação de um determinado tema. O que o indivíduo traz consigo de conhecimento e suas representações só podem ser acessadas por intermédio do diálogo. Para muitos educadores pode parecer perda de tempo saber o que o aluno pensa a respeito de determinado tema a ser ensinado, porém não é ignorando o que os alunos pensam que eles deixarão de pensar. Todos nós procuramos respostas para o que nos cerca, e se o educador tentar ensinar sem conhecer as representações de seus alunos dificilmente poderá contribuir para uma educação mais significativa.

Existem vários desafios a serem superados pelos professores em sala de aula, entre os quais se destacam dois: o de tentar suscitar o espírito investigativo dos alunos, o que significa fazer das aulas um objeto de seus interesses, e de escolher temas ou noções-núcleo, uma vez que são inúmeros os temas e a carga horária semanal é reduzida. Além disso, existe um programa oficial que, embora flexível, deve ser contemplado. Vários temas dizem respeito às Geociências possibilitando o diálogo e participação da Geologia no ensino escolar. Entretanto há dificuldades na divulgação de conhecimentos geológicos específicos já que trabalhos em escala local são geralmente desenvolvidos nos meios acadêmicos e os livros didáticos adotados nas escolas trabalham com exemplos e ilustrações geológicas mais globais que são importantes, mas, nem sempre trazem a contribuição específica que o professor deseja ou necessita.

Em geral as produções científicas que podem contribuir para aprofundamento de temas e com contextualizações, que nem sempre são possíveis com informações gerais, se limitam ao espaço acadêmico. A maior aproximação entre academia e o meio escolar poderá contribuir também para estimular o espírito investigativo e compreensão de acontecimentos específicos de uma região.

Ademais, temos nos deparado com um quadro onde o ensino na rede pública encontra-se em precárias condições. No último relatório em 2009 do PISA, que traz os dados obtidos pelos estudantes de cada estado em Matemática, Leitura e Ciências - quando a área principal avaliada foi Ciências, o Brasil obteve a $53^{\text {a }}$ colocação entre os 57 países avaliados, o que indica graves deficiências nesta área. A essa desestruturação educacional são atribuídos fatores de ordem política, pedagógica e social e tem-se estabelecido teorias, leis e projetos de ensino-aprendizado com o objetivo de tornar o ensino mais democrático e de melhor qualidade. Destacam-se entre estes os Parâmetros Curriculares Nacionais (Brasil, 1997, 1998, 1999, 2002) e a Lei de Diretrizes e Bases da Educação - LDB (2006), os quais surgem para nortear as práticas de ensino. Nesses documentos destacam-se diversas orientações entre elas a necessidade de melhorar e integrar os saberes, de considerar e valorizar os saberes dos alunos no processo escolar de ensino-aprendizagem e de contextualizar o conteúdo a ser ensinado. A maioria dos brasileiros tem acesso à educação pública, o desafio agora é o de torná-la de qualidade.

Diante desse quadro como as Geociências podem contribuir para que tenhamos um ensino melhor? Como aproximar a produção científica da Geologia dos conhecimentos escolares? Como os saberes das Geociências podem estar mais integrados para construção de conhecimentos mais significativos para os alunos? Tendo a universidade como campo privilegiado de construção científica, estas são algumas das questões que se pretende abordar nesse trabalho.

\section{OBJETIVOS}

Diante das questões acima levantadas e pela carência de recursos didáticos na área das Geociências, especialmente no que se refere aos temas geológicos, foi que se propôs, no âmbito do Departamento de Geologia (IGEO/UFRJ), o fomento de atividades de divulgação do conhecimento geológico como forma de despertar o interesse das pessoas nessa área, promover a sua popularização, desenvolvendo recursos que facilitem o entendimento de temas relacionados à Geologia em diversos segmentos da sociedade, contribuindo assim para o enriquecimento cultural e melhorias na qualidade dos ensinos fundamental e médio.

Dessa forma, este artigo objetiva relatar as ações desenvolvidas no Departamento de Geologia/ IGEO/UFRJ que tem colaborado na divulgação do conhecimento geológico através práticas interdisciplinares de ensino tendo como base os conceitos geológicos. Essas ações incluíram:

a) a oferta de cursos de capacitação em diversos temas das Geociências a professores do ensino médio e fundamental da rede pública;

b) a elaboração de coleções didáticas dos principais tipos de rochas ígneas, metamórficas e sedimentares, como também dos principais 
tipos de minerais formadores de rochas com textos explicativos, que estão sendo distribuídas aos professores das escolas públicas do estado do Rio de Janeiro, e

c) livros paradidáticos com ênfase em educação ambiental.

\section{GEOLOGIA NO ENSINO BÁSICO}

Ciências da Terra e Geociências são utilizadas como sinônimos. Para Carneiro (2004) a missão central da Geologia é entender como funciona o planeta e determinar as causas dos fenômenos e as Ciências da Terra nasce para contemplar algumas limitações dessa abordagem favorecendo concepção integradora de Geologia.

Em relação ao termo Geologia existem várias definições. Segundo o glossário da Universidade de Brasília, Geologia é o estudo da Terra e, associadamente, de outros corpos extraterrestres, através de métodos ou técnicas diretos e indiretos nas mais diversas escalas, buscando determinar: as características físicas e químicas, retratadas nas várias fases sólidas, líquida e gasosa; a organização e estruturas internas e superficiais; os registros de vida e, por estudos comparados, a evolução histórica dos processos envolvidos na formação da Terra ou da região em estudo.

Guimarães (2004) entende que a Geologia, ao lado de sua forma de raciocínio e métodos próprios de investigação, integra os conhecimentos da Química, da Física, da Biologia, da Matemática e mesmo das Ciências Humanas para o conhecimento e representação do geoambiente, fornecendo as bases para a contextualização sociocultural. Toledo (2002) enfatiza a importância dos materiais geológicos como fontes de matéria prima e a importância dessa ciência na prevenção e mitigação de problemas ambientais.

Segundo Santana e Barbosa (1993) as primeiras discussões sobre ensino da Geologia no Brasil, nos primeiro e segundo graus, datam do final da década de 1960. Nesta época teriam sido produzidos os primeiros materiais didáticos destinados a estes níveis de escolaridade. No entanto, depois de mais de quatro décadas, observa-se que ainda existe dificuldade de compreensão dos conceitos relacionados ao meio físico por parte de alunos e professores do ensino fundamental.

Segundo Compiani (2005), provavelmente o primeiro trabalho em Geociências para o ensino básico foi de Pedemonte (1992), que enumera uma série de problemas cognitivos e epistemológicos para o ensino/aprendizagem de Geologia na escola elementar. Segundo este autor o estudo de Pedemonte aponta as limitações e alerta para poucos pontos possíveis de serem trabalhados neste período educacional. Na mesma década Imbernon et a.l (1994) também destacaram um aumento do conteúdo em Geociências nos programas ministrados no ensino básico (antigos primeiro e segundo grau) no Brasil, passando de menos de $20 \%$ do conteúdo oferecido na década de 50 para $40 \%$ na década de 1980.

Muitos outros educadores já demonstraram a importância do ensino da Geologia no ensino básico e da sua divulgação científica. Carneiro et al. (2004) apresentaram dez razões pelas quais a inserção de cultura geológica beneficiará o ensino brasileiro, obedecendo às diretrizes educacionais atuais e discutem a respeito de alguns obstáculos no ensino e divulgação da Geologia quando comparada a outras ciências: a) a escala de tempo da maior parte dos processos geológicos envolve valores de muitos milhões de anos, o que, aparentemente, torna o discurso dos geólogos praticamente irrelevante face à necessidade de resolução, em tempo útil, de problemas concretos atuais; b) a escala espacial da análise geológica varia do submicroscópico ao planetário, percorrendo um intervalo demasiado vasto para a compreensão do leigo e c) é pouco difundida a noção de que a nossa sociedade contemporânea, altamente tecnológica e industrializada, se assenta, em grande parte, no aproveitamento de materiais geológicos.

Compiani (2005) aponta outro obstáculo para o ensino de conhecimentos geológicos, a comunidade científica. Para esse autor, a proposta de ensinar Geologia no ensino fundamental $\left(6^{\circ}\right.$ ao $9^{\circ}$ anos $)$ choca-se com a opinião da maioria dos geólogos e de muitos educadores que acreditam ser a natureza sintética e complexa do conhecimento geológico impeditiva para ensinamentos a esta faixa de idade, até mesmo os traços rudimentares de Geologia. Da parte dos geólogos, expõe o autor, observa-se que esta predominante ideia deriva de concepções de ciências e por consequência de um modo de olhar o ensino/aprendizagem deste nível com a cabeça da universidade, ou seja, com os parâmetros hierarquizados e sistematizados da Geologia.

A "impopularidade" do conhecimento geológico pode estar relacionada a diversos fatores, tais como o fato da maioria das pessoas ter maior interesse pelos seres vivos do que os inertes a exigência 
de uma maior abstração para o seu entendimento, falhas no sistema educacional e desinteresse dos geólogos (Uceda, 1996; Mondejar, 2007; Mansur, 2009).

Independentemente de fragilidades relativas aos obstáculos no ensino das geociências, à graduação dos professores e incorreções conceituais encontradas em livros a educação é um processo contínuo e que se aprimora através de construções coletivas de pesquisa. A divulgação da Geologia e de propostas educacionais no campo das Ciências da Terra tem aumentado no Brasil como pode ser observado através de trabalhos realizados em congressos e temas geológicos abordados nos meios de comunicação.

Portanto, no que se refere às ações desenvolvidas nessa instituição e discutidas nesse artigo, consideramos que elas não constituem uma inovação pedagógica, contudo se constituem como elementos nessa cadeia de responsabilidade acadêmica na transferência de saberes e construção coletiva, devendo ser compartilhadas e discutidas.

\section{METODOLOGIA}

Considerando que o número de matrículas no ensino básico totalizou 50.545.050 em 2012 (Inep 2013), os professores dos ciclos fundamental e médio constituem por excelência os grandes divulgadores de conhecimento, daí, as atividades serem oferecidas preferencialmente para esse grupo. Esses professores seriam o elo que uniria a escola e a universidade na difusão do conhecimento produzido nessa última.

\section{Concepções filosóficas e pedagógicas}

Em todas as atividades desenvolvidas adotou-se como orientação pedagógica, a Aprendizagem Significativa de David Ausubel que faz conjecturas a respeito dos processos mentais, estabelecendo possíveis caminhos da aprendizagem, entre estes, a construção de materiais didáticos. Segundo este autor, a aprendizagem dependerá da vontade do aprendiz que aprende e escolhe a forma pela qual irá desenvolver esse processo. Para Ausubel (1965, 1968) o que existe de mais importante é o que o aluno traz consigo de conhecimento porque somente através dos conhecimentos prévios pode-se ensinar de forma consequente.

$\mathrm{Na}$ teoria ausubeliana a aprendizagem significativa integra e organiza o material a ser aprendido (conceitos, ideias, preposições) numa estrutura cognitiva.

Para que novas ideias sejam aprendidas é necessário que os conceitos mais relevantes estejam claros e disponíveis na estrutura cognitiva, para que haja uma ancoragem de novas ideias e conceitos. Desta forma novos materiais podem ser aprendidos e retidos na medida em que conceitos fundamentais e inclusivos estejam esclarecidos na estrutura cognitiva do indivíduo.

A experiência cognitiva não se restringe apenas à influência direta dos conceitos já aprendidos sobre os componentes da nova aprendizagem, mas abrange também modificações significativas na estrutura cognitiva pela influência do novo material. Segundo Ausubel, o principal no processo de ensino é que a aprendizagem seja significativa, isto é o material a ser aprendido precisa fazer algum sentido para o aluno. Isto acontece quando a nova informação "ancora-se" nos conceitos relevantes já existentes na estrutura cognitiva do aprendiz (área de conhecimento do indivíduo). Neste processo a nova informação interage com uma estrutura de conhecimentos específica, a qual Ausubel define como conceitos subsunçores, existentes na estrutura cognitiva do indivíduo.

Quando um novo material é introduzido na estrutura cognitiva do indivíduo ele sofre modificação pela associação ao material aí existente, chamado de subsunçor. Nessa associação o material preexistente que modificou a nova informação e serviu de ancoradouro é também modificado pelo novo material. Ou seja, o conhecimento permite continuamente a resignificação das ideias. Entretanto, há situações em que os estudantes não possuem subsunçores relacionados aos novos conceitos; nesses casos Ausubel propõe utilizar organizadores prévios como estratégia para ensino-aprendizagem. Organizadores prévios são materiais introdutórios, apresentados a um nível mais alto de abstração, generalidade e inclusividade que o conteúdo do material instrucional a ser aprendido e se destinam a servir como pontes cognitivas entre aquilo que o aprendiz já sabe e o que ele deve saber para que possa aprender significativamente o novo conteúdo (Moreira 2008).

A proposta é de participação ativa do aluno, que não deve ser confundida com atividade física. O aluno deve ser capaz de reelaborar através das suas experiências e conhecimentos o que aprendeu. Desta forma a negociação de significados através de diálogo entre professor e alunos deve 
ser estimulada.

\section{Cursos de Aperfeiçoamento para Professores}

No Departamento de Geologia/IGEO/UFRJ são oferecidos dois cursos de aperfeiçoamento para os professores da rede pública de ensino do estado do Rio de: Geologia Geral para o Ensino Básico e Rochas e Minerais para o Ensino Básico. Esses cursos são certificados pela Pró-Reitoria de Extensão da Universidade Federal do Rio de Janeiro.

Um dos primeiros procedimentos adotados na elaboração dos referidos cursos foi o levantamento de informações gerais que permitiram a seleção de conteúdos e materiais didáticos dos ensinos fundamental e médio relacionados a temas pertinentes às Geociências, contidos nas disciplinas de Geografia e Ciências. Estes conteúdos serviram como base para a elaboração dos programas ministrados nos cursos de aperfeiçoamento da UFRJ. Como exemplo de conteúdo podemos citar "o lugar como a experiência vivida dos homens com o território e paisagens; Planeta Terra: a nave em que viajamos; formas de relevo, litosfera, movimentos tectônicos, erosão, desertificação, água, atmosfera, ambiente de florestas, cerrados, semiáridos, pontos cardeais, coordenadas geográficas", abordados dentro da disciplina de Geografia nos $6^{\circ}$ e $7^{\circ}$ anos do ensino fundamental (PCN do MEC, 1998).

Os materiais consultados abrangem:

a) livros de Ciências e Geografia do segundo ciclo do ensino fundamental que fazem parte do Plano Nacional do Livro Didático (PNLD) do Ministério da Educação e Cultura (MEC; Brasil, 2007a, 2007b) utilizados na rede pública de ensino. Esses materiais foram selecionados para este trabalho por orientar as práticas educacionais e conteúdos dos professores na maioria das escolas públicas da rede de ensino constituindo, muitas das vezes, o único material de apoio disponível para alunos e professores.

b) documentos do Ministério da Educação e Cultura (MEC) e da Secretaria Municipal de Educação (SME), da Secretaria de Estado de Educação do Rio de Janeiro (SEEDUC) e do Ministério da Educação, que incluem os Parâmetros Curriculares Nacionais do Ensino Médio e Fundamental (Brasil, 1997, 1998, 1999, 2002) e as Propostas Curriculares das disciplinas de Ciências e Geografia da SME e da SEEDUC $(2009,2010)$.

\section{Coleções Didáticas de Minerais e de Rochas}

Exemplares de minerais e de rochas que apresentaram boas condições didáticas (baixo grau de alteração, representatividade mineralógica, estética) foram inicialmente lavados com água e sabão e colocados para secar naturalmente. Posteriormente foram descritos, e quando necessário, reduzidos a dimensões que pudessem ser contidos nos compartimentos das caixas organizadoras e ainda assim resguardar suas feições características.

\section{APRESENTAÇÃO DE DADOS}

\section{Cursos de Aperfeiçoamento para Professores}

Foram realizadas duas edições do curso Geologia Geral para o Ensino Básico (janeiro/2010 e julho/2011) e uma edição do curso Rochas e Minerais para o Ensino Básico). Os cursos foram organizados com aulas pela manhã e oficinas à tarde. Objetivou-se integrar teoria à prática, aperfeiçoar conhecimentos geológicos através das aulas expositivas e apresentar atividades que pudessem servir de suportes didáticos para os professores.

Os orientadores prévios utilizados foram preenchimento de questionários no início das aulas no qual constavam perguntas gerais relativas ao tema a ser abordado na aula do dia; imagens relativas aos temas, questionamentos sobre eventos geológicos ocorridos ou presentes no estado do Rio de Janeiro (como por exemplo, vulcões, terremotos, cadeias de montanhas, deslizamentos); filmes, imagens, um questionamento filosófico, etc. Os orientadores prévios incentivaram o diálogo e o debate promovendo discussões de forma crítica e científica.

\section{Tema I}

Na primeira oficina representou-se a Teoria do Big Bang através de atividade artística educativa (Fig. 1). O organizador prévio para atividade (Big Bang) pode ser uma imagem do universo através da qual se constrói relação dialógica que indique os conhecimentos prévios do público (Ausubel, 1978). Neste diálogo pode-se apresentar questões gerais relacionadas ao tema da aula. Com essa atividade os interlocutores poderão resignificar seus conhecimentos. A situação-problema desta atividade encontra-se na representação do conceito através dos materiais apresentados. A atividade de construção do sistema solar traz como proposta o 
desenvolvimento de aula interdisciplinar das áreas das Ciências da Terra, Geografia ou Ciências, e Matemática. Pretendeu-se desenvolver habilidades comparativas utilizando para isso os diâmetros entre os planetas do Sistema Solar. Outra sugestão, apresentada por aluna do curso, é comparar as distâncias entre os planetas com distâncias reais. Adota-se como referencial um ponto conhecido pela maioria do grupo, por exemplo, a escola, e estabelecer distâncias proporcionais entre essa e o Estádio do Maracanã.

A intencionalidade pedagógica do uso de material concreto no ensino da astronomia nas séries do ensino básico é uma prática bastante comum, juntamente com outros tipos de metodologia. A relação com lendas e histórias conhecidas e vivências diárias o entendimento de fases da lua, conceitos de marés, clima e dimensões, órbitas e distâncias planetárias (por ex., Martins, 2008; Gentile, 2014).

A interação estabelece relações entre sujeito e objeto, ou seja, entre o saber e o sujeito que conhece. Nesse sentido construir conhecimentos é estar em relação com o mundo, conhecendo-o através da experiência (física ou lógica), as quais muitas vezes não tem relação direta com o material em si utilizado, mas sim com a experiência pessoal do sujeito, somado as seus saberes anteriores frente ao novo objeto de conhecimento (Bartelmebs, 2012).

\section{Tema II}

Neste tema representaram-se as camadas da Terra em lata de leite. Sugere-se que o estudante considere a altura da lata como o raio da Terra, e represente as profundidades das camadas em escalas correspondentes. O organizador prévio para atividade é uma figura da estrutura interna da Terra; ao se trabalhar com a relação de escalas pode-se incorporar o sentido real das diferentes espessuras das camadas da Terra, o que muitas vezes não é percebido apenas olhando imagens exibidas pelo professor. À semelhança da oficina sobre o sistema solar, esta também traz uma proposta de interdisciplinaridade com a Matemática ao se trabalhar com grandezas numéricas diferentes e com outras áreas da Geografia ao se abordar transformação de escalas.

\section{Tema III}

Em relação ao tema Placas Tectônicas, o recurso desenvolvido foi um quebra-cabeça construído com lata de leite, imãs e mapa das placas tectônicas. (Fig. 2). O organizador prévio escolhido pode ser
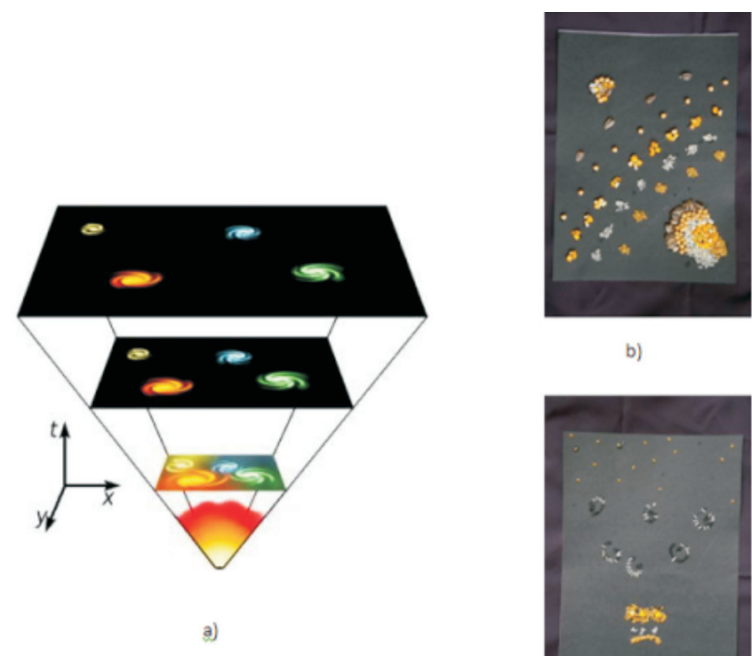

b)

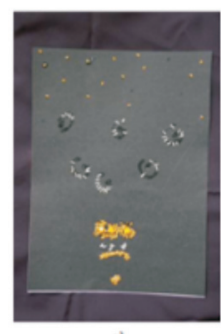

c.

Figura 1. a) Esquema do Big Bang, b) e c) modelos construídos com grãos por alunos no curso de atualização de professores, janeiro 2010

imagem de um vulcão ou um filme sobre terremoto, porque, em geral, são assuntos conhecidos que causam fascinação. O objetivo é que no processo de construção desta atividade os alunos compreendam que a Terra é formada por placas que se movimentam e que esses movimentos ocasionam tais fenômenos.

$\mathrm{Na}$ construção do mapa de placas tectônicas, ocorreu dificuldade de realizar a atividade proposta porque a projeção plana, indicada como tarefa, fazia com que as bordas do mapa se apresentassem geometricamente inadequadas, sobrando ou faltando partes a serem encaixadas. Depois de várias tentativas uma das alunas sugeriu que a projeção cilíndrica seria mais adequada para este mapa. Como proposto pelo cognitivismo e nos PCNs deve-se

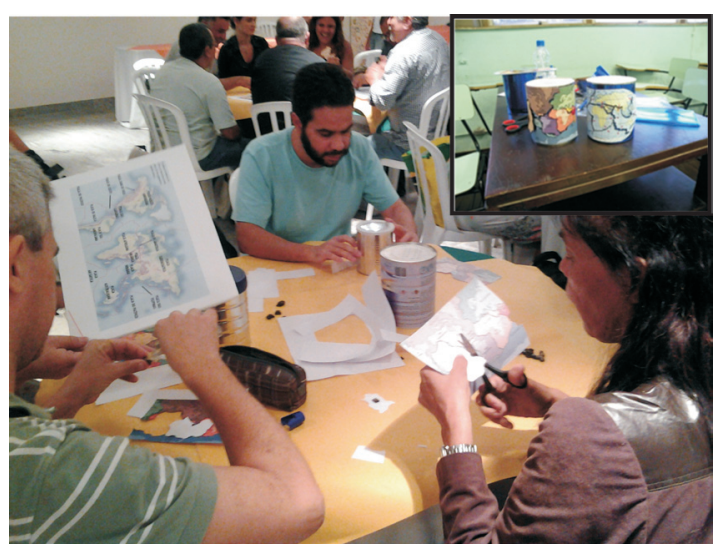

Figura 2. Mapa das placas tectônicas em lata de leite, material feito por alunos do curso de atualização de professores 
atentar para o processo de aprendizagem. Neste caso mais importante do que fazer o correto, que era indicado pela atividade, foi participar do processo produtivo, pois diante da situação-problema achou-se uma resposta melhor do que a proposta. Em aula tradicional, diretiva, provavelmente essa resposta mais adequada não teria surgido.

\section{Tema IV}

Com o tema Geomorfologia buscou-se explorar a utilização da ferramenta do Google Earth para gravação de vídeo aéreo mostrando o relevo do estado do Rio de Janeiro. Segundo o PCNEF (1997) é indiscutível a necessidade crescente do uso de computadores pelos alunos como instrumento de aprendizagem escolar, para que possam estar atualizados em relação às novas tecnologias da informação e se instrumentalizarem para as demandas sociais presentes e futuras. Desta forma, é indispensável que o professor tenha conhecimentos desta ferramenta e possa trabalhar habilidades e competências nesta área com os alunos.

\section{Temas V e VI}

Para os temas Água e Atmosfera apresentou-se painéis do ciclo da água das camadas da atmosfera e um quebra-cabeça da atmosfera (Fig. 3).

Atividades com organização de organograma foram inspiradas na teoria ausubeliana de organização dos materiais mentais e tiveram continuidade e difusão com os mapas conceituais de Novak (1999). Os mapas mentais são ferramentas gráficas visando organizar e representar o conhecimento, estruturados a partir de conceitos fundamentais e suas relações. Geralmente, os conceitos são destacados em caixas de texto. A relação entre dois conceitos é representada por uma linha ou seta, contendo uma "palavra de ligação" ou "frase de ligação". Sendo assim, mapas conceituais têm por objetivo reduzir, de forma analítica, a estrutura cognitiva subjacente a um dado conhecimento, aos seus elementos básicos.

Em geologia pode-se utilizar mapas conceituais para explicar vários temas como ciclo das rochas, ciclo das águas, esquemas diferenciativos para classificar tipos de rochas, etc.

\section{Tema VII}

O painel do ciclo das rochas pretendeu estruturar os conteúdos conceituais adquiridos em aula expositiva. A organização apresentada neste pai-

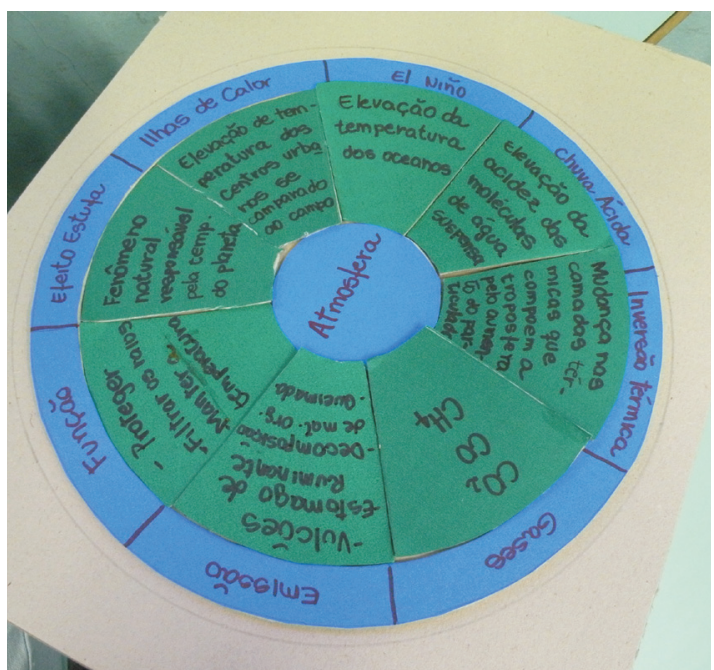

Figura 3. Quebra-cabeça didático, na forma de mandala, sobre o tema atmosfera, construído por aluna do curso de atualização de professores

nel também pode ser construída com ferramenta conhecida como mapa conceitual. Segundo Novak (1999) os mapas mentais constituem bons instrumentos educativos e podem ser desenvolvidos com alunos em sala de aula seguindo as seguintes etapas: a) ter, antes, uma boa pergunta inicial, cuja resposta estará expressa no mapa conceitual construído; b) escolher um conjunto de conceitos (palavras-chave) dispondo-os aleatoriamente no espaço onde o mapa será elaborado; c) escolher um par de conceitos para estabelecimento da(s) relação(ões) entre eles; d) decidir qual a melhor e escrever uma frase de ligação para esse par de conceitos escolhido; e) a repetição das etapas c) e d) tantas vezes quanto isso se fizer necessário.

No caso do painel dos ciclos das rochas desenvolvido neste trabalho as palavras-chave e as correlações já estão estabelecidas e o desafio é encontrar a melhor forma de organizá-los. Também para o tema Processos Geológicos e Ciclo das Rochas se desenvolveu atividade utilizando sementes (Fig. 4) com o objetivo de analisar energia do sistema, transporte, tamanho e deposição dos sedimentos. Como objeto subsunçor para esta atividade sugere-se ilustrações de praias ou rios.

\section{Tema VIII}

Nas oficinas do curso de Rochas e Minerais para o Ensino Básico optou-se por trabalhar nos laboratórios com amostras desses materiais, por apresentar maior potencial de aprendizagem e por ser um dos poucos momentos que os alunos têm para entrar em contato com os mesmos, já que a 


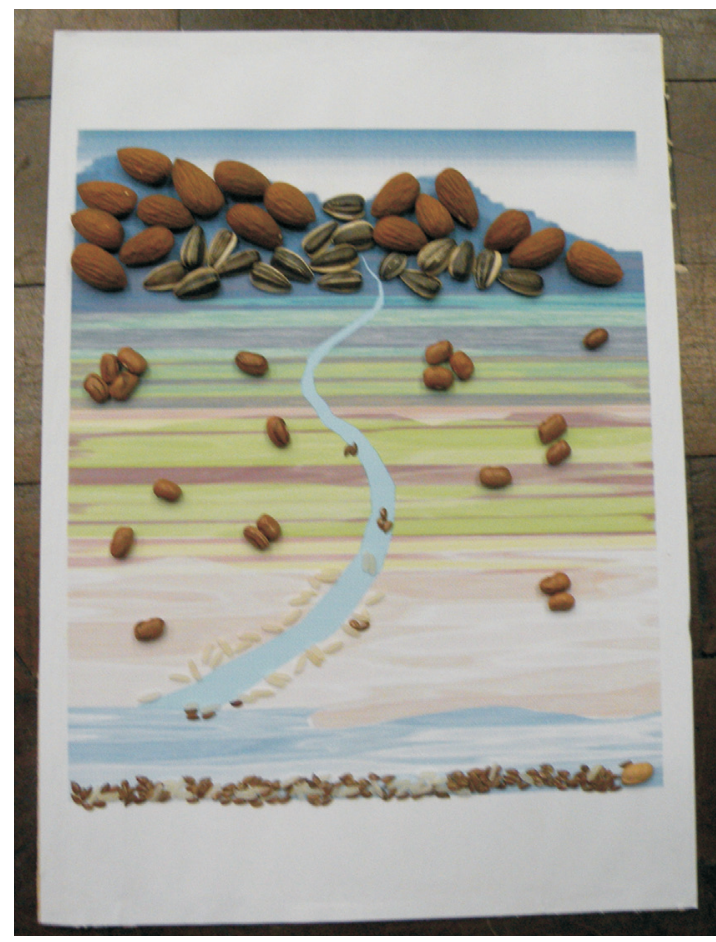

Figura 4. Painel representativo da energia, fragmentação, transporte e deposição de sedimentos do sistema

maioria das escolas públicas não os possui. Estas oficinas realizadas em laboratórios tiveram como objetivo desenvolver habilidades e competências de identificação e diferenciação de alguns minerais e rochas através de amostras de mão desses materiais.

Também foram apresentados durante esse curso jogos como um bingo sobre rochas ígneas e metamórficas, o qual se joga da forma popularmente conhecida e divulgada; jogo da memória sobre os minerais e seus usos ou sobre pedra bruta e gema lapidada. A variação de atividades constitui uma das maneiras de estimular a aprendizagem. A formação continuada é uma das formas de se aperfeiçoar desenvolvendo maneiras de ensinar e aprender. Atividades práticas como visitas guiadas e a museus, debate de filme e aulas em laboratório podem proporcionar meios de aprendizagem mais eficientes quando associadas a aulas expositivas. Quando o aluno busca conhecer o material com o qual tem contato ou é solicitado a apresentar uma resposta para uma situação-problema ele se torna mais autônomo e crítico diante da realidade, a aprendizagem é significativa.

\section{Coleções Didáticas de Minerais e de Rochas}

A coleção de minerais é composta por 16 exemplares. Os exemplares constam de representantes da escala de dureza de Mohs, como também dos principais minerais formadores de rochas, e sua utilização como minério. A coleção de rochas é composta por 16 exemplares representativos dos três grandes grupos de rochas: ígneas, metamórficas e sedimentares. A seleção dos exemplares baseou-se em sua abundância na crosta terrestre, constituindo assim, as rochas mais conhecidas. Sempre que possível, essas amostras constituíam exemplares da cidade do Rio de Janeiro, para demonstrar a proximidade dessa geodiversidade no seu entorno.

Nos guias descritivos que acompanham as coleções, o texto é apresentado de forma acessível e agradável, rico em ilustrações coloridas. Durante a sua elaboração teve-se sempre em mente a complexidade da transformação do conhecimento científico para fins de ensino e divulgação, procurando-se não suprimir os saberes que se deseja compartilhar, não desenvolver uma linguagem simplista de forma que o produto final não refletisse um dos grandes problemas da divulgação científica - o texto empobrecido.

Propõe-se que estes guias sejam mais do que um atlas de minerais e de rochas considerando o leitor apenas como o receptor de informações permitindo que o leitor atue interativamente com o material de leitura descrevendo as amostras e levando-o também a outra mídia de conhecimento/ comunicação - a internet, procurando dessa forma

Viaje até a mina de calcita onde foi retirada a amostra que consta na sua coleção pelo google earth (www.google.earth).

Ao acessar a homepage do google earth peça para ir até Cachoeiro de Itapemirim (ES) - Brasil. Ao chegar lá atente para as coordenadas geográficas: 2043'54" S e 414ㄴ'44" W. Ao atingi-las você terá chegado a uma das 50 minas de mármore localizadas nesta região, que é o maior polo produtor de rochas ornamentais do Brasil (pedras usadas para revestir pisos, paredes, confecção de mesas, balcões, etc.). As pedras do Espírito Santo são vendidas para vários países, como o Japão e a Itália.

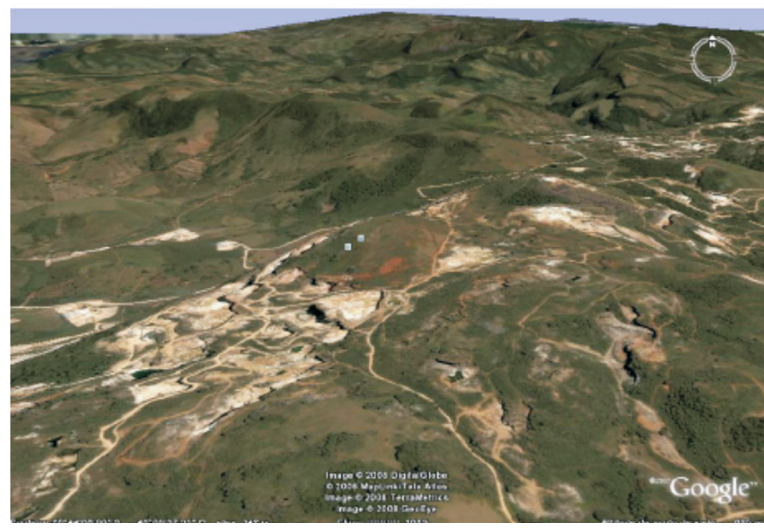

Figura 5. Instruções para que o leitor utilize a mídia Internet 
explorar as atividades e habilidades que as crianças e jovens da atualidade sentem prazer em exercer. $\mathrm{O}$ processo de interatividade neste guia é feito quando o leitor ao ler a descrição do mineral recebe informações para trabalhar com o google earth e "viajar" até as minas e ocorrências onde as suas amostras foram coletadas (Fig. 5). Este processo permite o estudante conhecer a diversidade das proveniências dos minerais e promove a integração com outras ciências: a Geografia, ampliando assim o seu entendimento a cerca do espaço em que vive e a Economia, quando também são transmitidas de forma sintetizada informações sobre a produção e uso desses minérios.

O conteúdo do guia descritivo das rochas refere-se à origem do Universo e da Terra procurando correlacioná-lo com os temas seguintes - os processos formadores dos três grupos de rochas (ígneas, metamórficas e sedimentares) e o ciclo das rochas. Relata também as informações que as rochas nos fornecem sobre a história da Terra e da vida, além da conceituação dos parâmetros descritivos das rochas e de cada exemplar presente na coleção. Teve-se também a preocupação de escrever esses conteúdos de forma acessível e motivadora, procurando sempre relacionar exemplos e do cotidiano e conceitos já conhecidos antes de introduzir os conceitos acima referidos. No caso do conceito de ciclo das rochas, por exemplo, foi anteriormente introduzido o conceito de ciclo e exemplos de ciclos já conhecidos (Fig. 6); no caso da descrição das rochas ígneas foi mostrado que as pessoas são também diferentes e o reconhecimento de cada uma segue determinados critérios (Fig. 7). A seguir foram apresentados os termos descritivos das rochas ígneas: cor, granulação, textura, estrutura, formas dos corpos rochosos e composição mineralógica (Fig. 8).

O processo de interatividade também utiliza o google earth e incentiva o leitor "viajar" até o local onde as

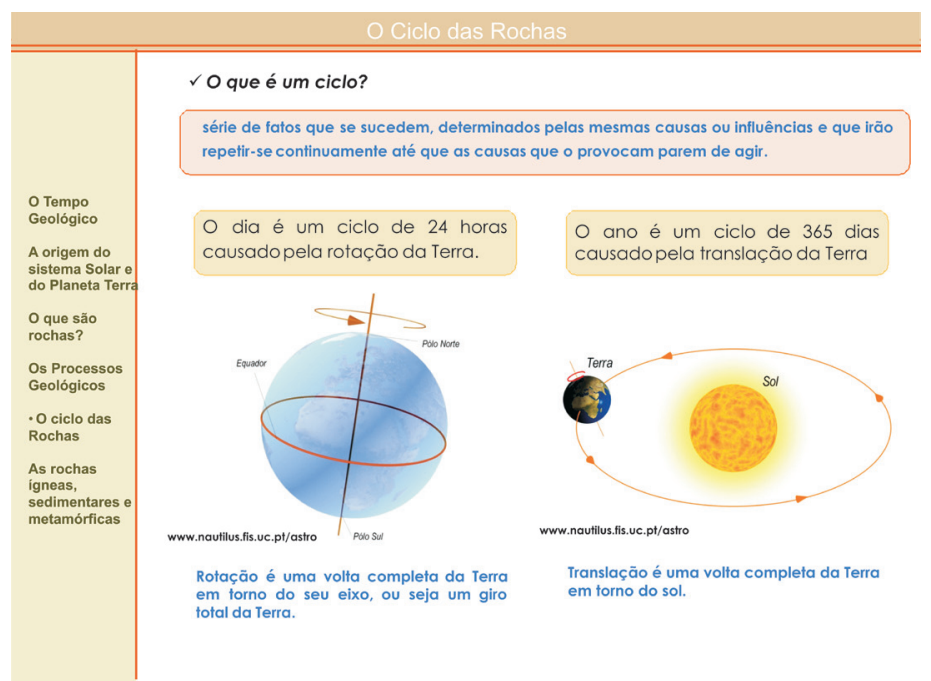

Figura 6. Conceituação de ciclo no guia descritivo das rochas

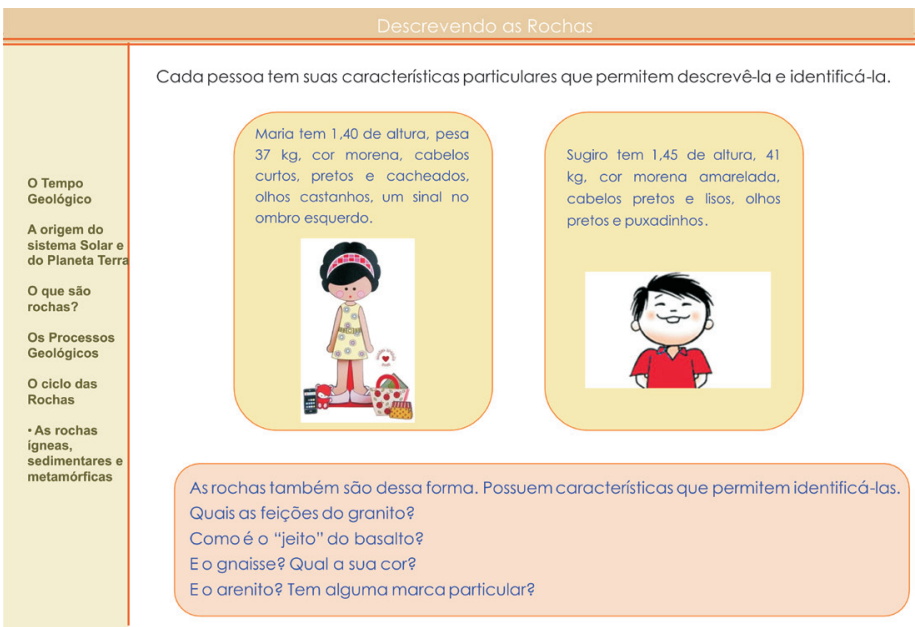

Figura 7. Correlação entre as características reconhecedoras das pessoas e as rochas

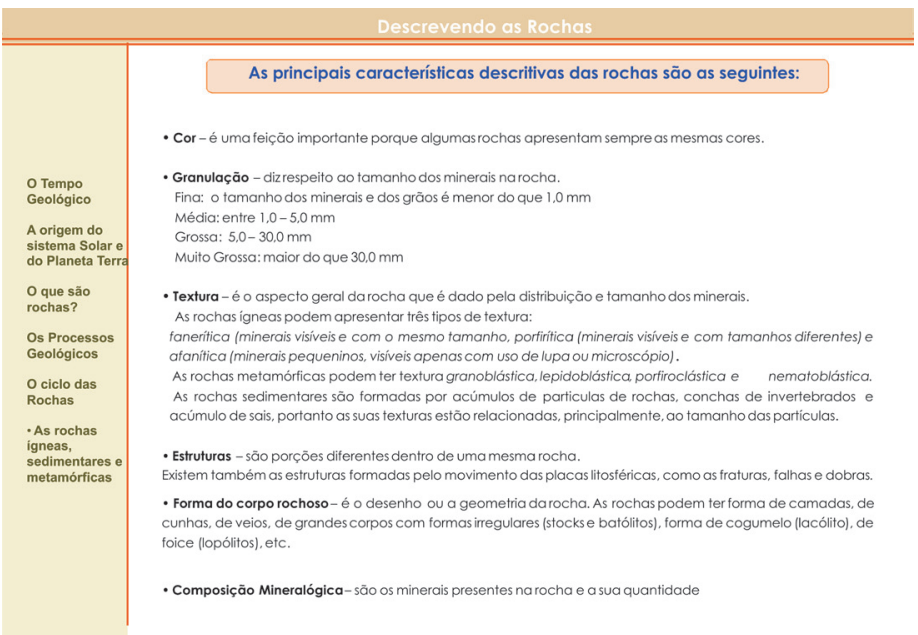

Figura 8. Lâmina apresentando os termos descritivos para rochas ígneas 
rochas foram coletadas. Ademais, incluem-se aí algumas informações complementares promovendo a integração do saber, como por exemplo, a formação da rocha e a história geológica do Rio de Janeiro (Fig. 9).

\section{DISCUSSÃO E CONSIDERAÇÕES FINAIS}

Como forma de avaliar as atividades desenvolvidas, foi distribuído um questionário aos oitenta e nove participantes que perfazem o público total das cinco edições dos cursos oferecidos na UFRJ. Trinta por cento dos participantes responderam o questionário, cujos resultados encontram-se compilados na tabela 1.

A análise dos resultados demonstrou que $77 \%$ dos participantes consideraram o curso ótimo, $18 \%$ bom, $5 \%$ regular. A análise do conhecimento adquirido foi contemplada nas questões compreensão do conteúdo programático e o curso atendeu as suas expectativas? Por quê? Todos consideraram que o curso atendeu as suas expectativas pelos seguintes motivos: maior aprendizado e aprofundamento de conteúdo, atividades práticas que podem ser desenvolvidas em sala de aula, conteúdo sintetizado e diversificado.

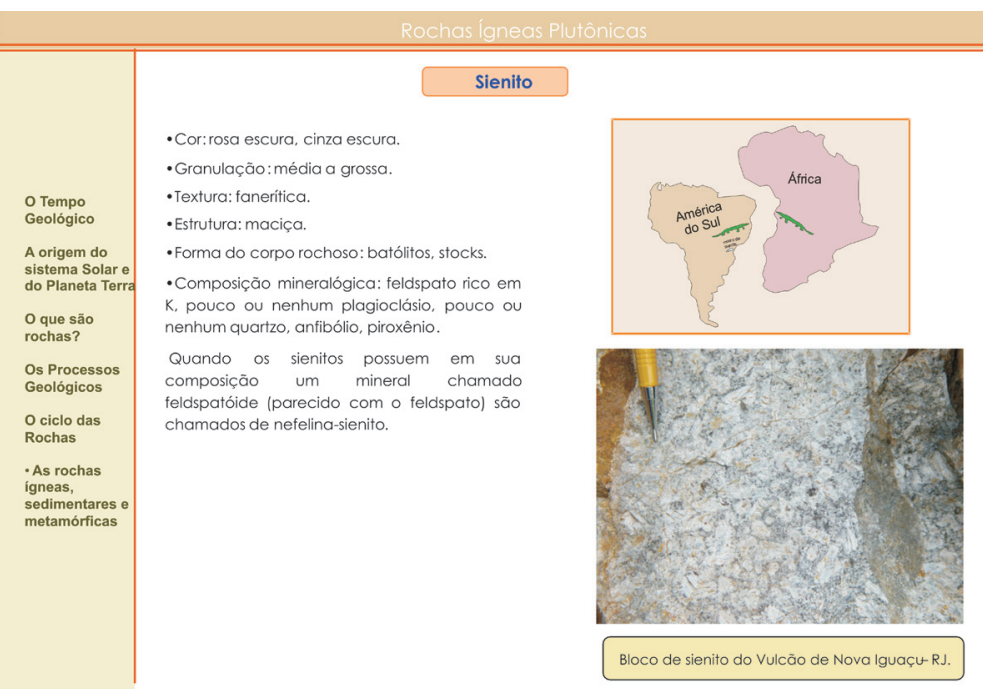

Figura 9. Texto mostrando a ocorrência de sienito no Rio de Janeiro e que sua formação se deu quando Brasil e África foram separados

Tabela 1 - Resultado da avaliação pelos participantes do curso

\begin{tabular}{|c|c|c|c|c|}
\hline \multirow{2}{*}{ Itens Avaliados } & \multicolumn{4}{|c|}{ Valores atribuídos (\%) } \\
\hline & ótimo & bom & regular & ruim \\
\hline \multicolumn{5}{|l|}{ Programa e Conteúdo } \\
\hline Avaliação geral do curso & 77 & 18 & 5 & 0 \\
\hline Interesse despertado pelo curso & 96 & 4 & 0 & 0 \\
\hline Compreensão do conteúdo apresentado & 83 & 17 & 0 & 0 \\
\hline Carga horária & 52 & 44 & 4 & 0 \\
\hline Relação do curso com as suas atividades profissionais & 87 & 13 & 0 & 0 \\
\hline Material didático & 87 & 13 & 0 & 0 \\
\hline \multicolumn{5}{|l|}{ Professores e Organizadores } \\
\hline Relacionamento do instrutor com o grupo & 82 & 9 & 9 & 0 \\
\hline Apoio do instrutor ao grupo para a realização das atividades & 83 & 13 & 4 & 0 \\
\hline Domínio do conteúdo pelo instrutor & 91 & 9 & 0 & 0 \\
\hline \multicolumn{5}{|c|}{ Atividades, Oficinas e Laboratórios } \\
\hline Interesse despertado pelos laboratórios e oficinas & 91 & 9 & 0 & 0 \\
\hline Organização das oficinas & 91 & 9 & 0 & 0 \\
\hline Material disponibilizado nas oficinas & 65 & 35 & 0 & 0 \\
\hline Possibilidade de desenvolvimento das oficinas em salas de aula & 100 & 0 & 0 & 0 \\
\hline
\end{tabular}


Geologia da UFRJ voltado a professores da rede pública de ensino; avaliação de atividades e material didático para o campo das Geociências e análise de sua aplicabilidade com professores e alunos desta área, o que contribuiu para modificação de alguns desses materiais; trocas de experiências, informações e debates sobre questões científicas e sociais entre profissionais e estudantes da área de educação; distribuição de materiais paradidáticos para os alunos do curso, a saber: coleção de minerais e rochas, com seus guias descritivos e dois CD's: um com o conteúdo das aulas e outro das oficinas.

\section{Agradecimentos}

Os autores agradecem à Fundação de Amparo à Ciência do Estado Rio de Janeiro (FAPERJ), cujo incentivo financeiro para projetos (processos n ${ }^{\circ}$. E-26/ 170.447/2005, E-110.125/2008 e E-26.111637/2012) permitiram a realização deste trabalho. Os autores também agradecem os comentários, recomendações e sugestões indicadas pelos revisores, as quais trouxeram relevantes contribuições ao artigo apresentado.

\section{Referências}

Ausubel D.P. 1965. A cognitive structure view of word and concept meaning. In R.C. Anderson e D. Ausubel. Readings in the Psychology of Cognition. New York: Holt, Rinehart and Winston.

Ausubel D.P. 1968. Educational Psychology: Cognitive View. New York: Holt, Rinehart and Winston, Inc.

Bartelmebs R.C. 2012. A astronomia nos Anos Iniciais: Reflexões de Uma Comunidade de Prática. In: IX Semin. Pesq. Educ. Região Sul, Caxias do Sul. Anais ... p:1-16.

Brasil. 1996. Lei de Diretrizes e Bases da Educação Nacional. Brasília: MEC.

Brasil. Ministério da Educação. 1999. Parâmetros Curriculares Nacionais para o Ensino Médio. Brasília: Secr. Educação Média e Tecnológica (Semtec/MEC).

Brasil. Ministério da Educação. 2002. PCN+, Orientações Educacionais Complementares aos Parâmetros Curriculares Nacionais. Brasília: MEC.

Brasil. Ministério da Educação. 2007a. Guia de livros didáticos PNLD 2008: Geografia. Brasília: MEC.

Brasil. Ministério da Educação. 2007b. Guia de livros didáticos PNLD 2008: Ciências. Brasília: MEC.

Brasil. Ministério da Educação. Secr. Educação Fundamental. 1998a. Parâmetros curriculares nacionais: Geografia. Brasília: MEC/ SEF.

Brasil. Ministério da Educação. Secr. Educação Fun- damental. 1998b. Parâmetros curriculares nacionais: Ciências. Brasília: MEC/ SEF.

Brasil. Secretaria de Educação Fundamental. 1997. Parâmetros Curriculares Nacionais: introdução aos parâmetros curriculares nacionais (v.1). Brasília: MEC/SEF.

Carneiro C.D.R., Toledo M.C.M.; Almeida F.F.M. 2004. Dez motivos para a inclusão de temas de geologia na educação básica. Rev. Bras. Geoc., 34(4): 553-560.

Compiani M. 2005. Geologia pra que te quero no ensino de Ciências. Campinas: Educ. \& Soc., (36):100-117.

Gentile P. 2014. Era uma vez o Sol, a Terra e a Lua... Rev Nova Escola. http://revistaescola.abril.com. $\mathrm{br} /$ ciencias/pratica-pedagogica/era-vez-sol-terra-lua-426157.shtml)

Guimarães E.M. 2004. A contribuição da Geologia na construção de um padrão de referência do mundo físico na educação básica. Rev. Bras. Ge$o c$, 34:87-94.

Imbernon R.A.L., Sígolo J.B., Toledo M.C.M.de. 1994. Análise crítica dos conhecimentos em Geociências de Alunos de $1^{\circ}$., $2^{\circ}$. E $3^{\circ}$. Graus e professores de $1^{\circ}$. E $2^{\circ}$. Graus. Primeiros Resultados. Cadernos IG/UNICAMP. Vol. Esp. (2).

INEP. Instituto Nacional de Estudos e Pesquisas Educacionais. 2013. http://www.inep.gov.br/. Página visitada em 30/10/2014.

Mansur K.L. 2009. Projetos Educacionais para a Popularização das Geociências e para a Geoconservação. São Paulo: Geol. USP, Publ. espec., 5:63-74.

Martins A.R. 2008. Lá vem o sol. Revista Escola. (http:// revistaescola.abril.com.br/ciencias/fundamentos/ la-vem-sol-425975.shtml).

Mondéjar F.G. 2007. El Patrimonio Geológico: cultura social y ordenación del territorio. In: Congr. Intern. Geologia Y Mineria em la Ordenación del Territorio Y en el Desarrollo, 1., Utrillas. Librillo Preliminar de Actas... Utrillas: SEDPGYM, p. 6-7.

Novak J.D., Gowin D.B. 1999. Aprender a aprender. 2 ed. Trad. Carla Valadares. Portugal: Plátano Ed. Técn.

Pedemonte G.M. 1992. La didattica delle scienze della Terra: alcuni problemi modali per l'insegnamento e 1'apprendimento. Annali della pubblica intruzione, 38(5-6):579-592.

PISA. Programa Internacional para Avaliação de Alunos. s.d. www. http://pisa2009.acer.edu.au/downloads.php (página visitada em 07/06/2012).

Rio de Janeiro. Secretaria de Estado de Educação. 2009a. Orientações curriculares: áreas específicas/ Geografia. Rio de Janeiro.

Rio de Janeiro. Secretaria de Estado de Educação. 2009b. Orientações Curriculares: Áreas Específicas/ Ciências. Rio de Janeiro.

Rio de Janeiro. Secretaria de Estado de Educação. 
2010a. Proposta curricular: um novo formato/Geografia. Rio de Janeiro.

Rio de Janeiro. Secretaria de Estado de Educação. 2010b. Proposta curricular: um novo formato/Ciências, Biologia, Física e Química. Rio de Janeiro.

Santana J.C.B. Barbosa L.M. 1996. A realidade do ensino de Geociências no $2^{\circ}$ Grau em Feira de Santana, Bahia. Rev. Bras. Geoc., 23(1):98-106.
Toledo M.C.M. 2002. Geologia/Geociências no Ensino. In: Semin. Nac. Cursos de Geologia. Campinas: Univ. Est. Campinas.

Uceda A.C. 1996. El Patrimonio Geologico. Ideas para su Protección, Conservación y Utilización. In: MOPTMA. Min. Obr. Públ. Tranp. Med. Amb. El patrimonio geológico. Bases para su valoración, protección, conservación y utilización. Madrid.p.17-27.

RESUMO : A Geologia não é disciplina regular da educação básica no Brasil e seus conceitos não são populares, mas faz parte do cotidiano e ajuda as pessoas a compreender o meio em que vivem, podendo contribuir para melhorar o conhecimento de questões ambientais dentro e fora da escola. A Universidade, por vocação, deve multiplicador sua produção e repassar o conhecimento, minimizando a distância entre academia e sociedade. 0 Departamento de Geologia/IGEO/UFRJ oferece cursos de aperfeiçoamento para professores, visando divulgar o conhecimento geológico. As práticas interdisciplinares de ensino acerca de conceitos geológicos buscam contribuir para melhorar 0 ensino de Geociências na rede pública do Rio de Janeiro. Os recursos paradidáticos aproximam docentes e alunos da rede pública ao conhecimento, tendo sido capacitados cerca de 80 professores de vários municípios do Estado do RJ e distribuídas mais de 300 coleções de minerais e de rochas com guias explicativos. A Instituição torna-se agente de requalificação do ensino básico, fornecendo subsídios para atividades escolares e formando multiplicadores do conhecimento.

PALAVRAS CHAVE: Ensino em Geociências; divulgação científica, recursos paradidáticos. 